\title{
Dydrogesterone in the treatment of endometriosis: evidence mapping and meta-analysis
}

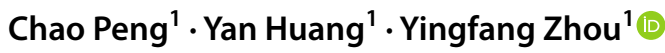

Received: 4 June 2020 / Accepted: 11 November 2020 / Published online: 4 January 2021

(c) The Author(s) 2021

\begin{abstract}
Purpose Endometriosis is a common, chronic gynecological disease that affects women's fertility potential. Dydrogesterone is an effective and safe drug that is under-utilized due to limited clinical research. The purpose of this evidence mapping is to identify, describe, and analyze the current available evidence regarding dydrogesterone for the treatment of endometriosis. Materials and methods We performed a search in electronic databases: Medline, The Cochrane Library, EMBASE, PubMed, CNKI, Wanfang, VIP, and CBM. We also hand-searched google for relevant studies. Our primary outcomes included changes in pain relief including pelvic pain, dysmenorrhea, and dyspareunia. Secondary outcomes included pregnancy rate, frequency of analgesic use, and other reported outcomes according to specific settings in the studies.

Results Of 377 references screened, 19 studies were included in the data synthesis involving 1709 female participants. Nearly three-quarters were either randomized control trials or clinical control trials. Compared with gestrinone, dydrogesterone relieved dysmenorrhea, increased the pregnancy rate, and reduced the risk of certain adverse events. Compared with GnRHa, dydrogesterone also lowered the risk of endometriosis recurrence and elevated transaminase levels. Whether there was any difference in efficacy between dydrogesterone and leuprolide acetate, letrozole or traditional Chinese medicine remains unclear due to insufficient data.

Conclusions The amount and quality of evidence evaluating the effects of dydrogesterone for the treatment of endometriosis is generally very low. Limited evidence suggests that dydrogesterone may have some advantages over gestrinone, $\mathrm{GnRH}$ agonists, and other therapeutic interventions in treating endometriosis. However, this conclusion should be interpreted with caution.
\end{abstract}

Keywords Dydrogesterone $\cdot$ Endometriosis $\cdot$ Evidence mapping $\cdot$ Gestrinone $\cdot$ GnRH agonist

$\begin{array}{ll}\text { Abbreviations } \\ \text { GnRH } & \text { Gonadotropin-releasing hormone } \\ \text { RCT } & \text { Randomized control trial } \\ \text { CCT } & \text { Clinical control trials } \\ \text { NOS } & \text { Newcastle-Ottawa Scale } \\ \text { VAS } & \text { Visual analogue score } \\ \text { AFS } & \text { American Fertility Society }\end{array}$

Yingfang Zhou

zhouyf8853@163.com

1 Department of Obstetrics and Gynecology, Peking University First Hospital, No. 8 Xishiku Street, Xicheng District, Beijing, China

\section{Introduction}

Endometriosis, defined as the presence of endometrial-like tissue outside the uterus, is a complex and chronic gynecological disease that affects women's fertility potential [1]. The prevalence of endometriosis has been estimated to be between 2 and $10 \%$ for women of reproductive age, and between 25 and $50 \%$ for women with infertility [2,3]. Although patients with endometriosis may be asymptomatic, most patients usually present with one or more associated symptoms, including dysmenorrhea, chronic pelvic pain, deep dyspareunia, cyclical intestinal complaints, fatigue/ weariness, and infertility [1]. Endometriosis-associated symptoms progressively impair the ability of women to carry out certain daily activities and result in worsening health status and overall well-being [4]. In addition, 2-4\% of women who are sexually active may have sexual dysfunction caused by this disease [5]. Endometriosis is also 
associated with considerable direct and indirect costs that is comparable to those resulting from major global chronic diseases such as diabetes. Finally, endometriosis-related symptoms substantially interfere with the employment of affected women, often resulting in several missed work days [4].

The etiology of endometriosis remains obscure. The development of endometriosis is a complex process with a large number of interconnected factors that may be both inherited and acquired [6]. Accumulating evidence suggests that immune cells, adhesion molecules, extracellular matrix metalloproteinase and pro-inflammatory cytokines activate or alter the peritoneal microenvironment, creating the conditions for differentiation, adhesion, proliferation, and survival of ectopic endometrial cells. New theories about the pathogenesis of endometriosis suggest it may originate from Müllerian or non-Müllerian stem cells, including those from the endometrial basal layer, Müllerian remnants, bone marrow, or the peritoneum. The innate ability of endometrial stem cells to regenerate cyclically also seems to play a key role. There is also evidence to support the hypothesis that ectopic Müllerian remnants of the endometrium, endocervix, and endosalpinx are 'leaked' from the genital ridge during organogenesis [7]. The dysregulation of hormonal pathways, as evidenced by increased estradiol production and progesterone resistance observed in women with endometriosis, has been a widely accepted theory about the pathogenesis of endometriosis [8].

It is now accepted that inflammation clearly plays a central role in the development and progression of endometriosis and is characterized by the overproduction of an array of inflammatory mediators such as prostaglandins, metalloproteinases, cytokines, and chemokines. The growth and adhesion of endometrial cells in the peritoneal cavity due to reactive oxygen species (ROS) and free radicals is thought to lead to disease onset, with its ensuing symptoms of pain and resultant infertility [9].

Symptomatic endometriosis remains the prime indication for treatment. Ideally, treatment should provide pain relief and allow pregnancy to occur safely while undergoing treatment. The current treatments for endometriosis include surgery (ablation using either laser or electrosurgery if laparoscopy is performed), pharmacological therapy, or a combination of both [10]. Symptomatic patients always receive pharmacological therapy, which can include: (i) analgesics for women with endometriosis-related pain, discuss the benefits and risks of analgesics, consider a short trial (for example, 3 months) paracetamol or a non-steroidal anti-inflammatory drug (NSAID) may provide adequate pain relief; (ii) hormonal treatments such as hormonal contraceptives, progestagens (e.g., progesterone), anti-progestagens (e.g., gestrinone), or gonadotropin-releasing hormone ( $\mathrm{GnRH})$ agonists (e.g., leuprolide) as it reduces endometriosis-associated pain [10]; (iii) alternative treatments: most recently, aromatase inhibitors (e.g., letrozole), traditional Chinese medicine, and acupuncture are considered potential therapies for endometriosis $[11,12]$. The choice of drug therapy is essential and should offer relief from symptoms without inhibiting ovulation, causing amenorrhea or other adverse effects.

Dydrogesterone (6-dehydro-retroprogesterone) is a retroprogesterone derived from progesterone that is similar in structure and pharmacology to endogenous progesterone. It acts as a selective progesterone receptor agonist and has better oral bioavailability compared with oral micronized progesterone [13]. Dydrogesterone has been on the market since the 1960s and is used as postmenopausal hormonereplacement as well as for treatment of menstrual disorders and endometriosis [14]. Dydrogesterone has been shown to relieve symptoms of endometriosis, regress lesions, and improve pregnancy rates in patients with infertility [15].

The proposed mechanism underlying the pharmacological action of progestogens involves the initial decidualization of endometrial tissue and eventual atrophy. Dydrogesterone causes atrophy of ectopic endometrium without suppressing the normal endometrium and simultaneously inhibits the development of new endometriotic lesions [16]. Furthermore, it does not inhibit ovulation and regular menstruation and does not induce weight gain and edema [15]. However, one study showed that a $2 \mathrm{mg}$ /day oral dosage of dienogest was more effective than a $10 \mathrm{mg}$ twice daily oral dosage of dydrogesterone for relieving endometriosis-associated pelvic pain, with a comparable safety profile [17].

Early clinical studies evaluating dydrogesterone efficacy and safety have been limited by small sample sizes and a lack of direct comparisons with control groups. Therefore, the aim of our study is to search and analyze available evidence surrounding the efficacy and safety of dydrogesterone in the treatment of endometriosis. To consolidate knowledge, avoid scientific redundancies, and identify research gaps, we provide a mapping of the empirical literature on the effects of dydrogesterone in the treatment of endometriosis.

\section{Materials and methods}

Evidence mapping of empirical literature on the effects of dydrogesterone in the treatment of endometriosis was performed.

\section{Data source}

We searched in the following electronic databases: Medline, The Cochrane Library, EMBASE, PubMed, CNKI, Wanfang, VIP, and CBM from inception to September 19, 2019. There was no limitation on publication status, publication dates, or language. The search strategy used in each database 
is presented in Appendix 1. We also hand-searched google for relevant studies.

\section{Study design}

All randomized control trials (RCTs), clinical control trials (CCTs), and observational studies were included in the evidence map.

\section{Participants}

We relied on the diagnosis of endometriosis as presented in the included studies.

\section{Interventions and comparisons}

Any studies that evaluated dydrogesterone alone were included in this evidence map without limitations regarding treatment dosage, frequency, and duration. There were no limitations on the number or types of the comparison. Furthermore, all single-arm studies without comparator were also included.

\section{Outcomes}

Primary outcomes included changes in pain relief including pelvic pain, dysmenorrhea, and dyspareunia. Secondary outcomes included the pregnancy rate, frequency of analgesic use, and other reported outcomes according to specific settings in the studies.

\section{Exclusion criteria}

a. Studies that were other than RCTs, CCTs, or observational studies;

b. Patients who were not diagnosed with endometriosis;

c. Studies that did not include dydrogesterone therapy;

d. Interventions that combined dydrogesterone with other therapies;

e. Language that was other than Chinese or English;

f. Studies with only an abstract and no full text.

\section{Study selection process}

Two reviewers $(\mathrm{CP}, \mathrm{YH})$ screened the search results. All potentially relevant citations were requested and inspected in detail via the full-text version. Disagreements were resolved by discussion with assistance from a third party (YFZ) if necessary. A PRISMA flow diagram was constructed to show the full study-selection process (Fig. 1).

\section{Data extraction}

Data from each study were extracted independently by two separate reviewers. A standardized data extraction form was designed and tested using a pilot data extraction exercise. Any disagreements were resolved by discussion with assistance from a third party if necessary. Where more information relating to a potentially includable study was lacking, we contacted study authors and requested further information. We extracted all relevant characteristics of included studies including:

a. General study characteristics (first authors, publication years, study location, center, and sample size);

b. Population characteristics including diagnosis, age, settings, inclusion and exclusion criteria;

c. Intervention characteristics including administration of interventions and treatment duration;

d. Outcome characteristics such as outcome category, definition of the outcome, and the time point of the measurement;

e. Key findings of each study.

\section{Data synthesis and analysis}

We used Revman 5.3 to conduct the meta-analysis. Before performing the meta-analysis, studies were judged homogeneous in terms of the characteristics of the study population, intervention used, outcomes, study design, and statistical metric. We used a random-effects model to pool the data. Statistical heterogeneity between the summary data was evaluated using the $I^{2}$ statistic ( $\leq 25 \%$ represents insignificant heterogeneity, 26-50\% represents low heterogeneity, $51-75 \%$ represents moderate heterogeneity, and $\geq 75 \%$ represents high heterogeneity). Where moderate/high statistical heterogeneities $\left(I^{2}>50 \%\right)$ were found, we explored the source of heterogeneity and tried to identify its cause. A subgroup analysis was performed if the causes of heterogeneity were identified. When the source or cause that induced heterogeneity could not be identified, we synthesized data using a random-effects model, and our confidence on the study findings was downgraded. We assessed publication bias by examining funnel plots when the number of trials reporting the outcomes was ten or more [18].

\section{Risk of bias assessment}

The risk of bias of included studies was assessed using the Cochrane risk of bias tool for interventional studies. The domains of risk of bias assessed included randomization, 
Fig. 1 PRISMA flow diagram

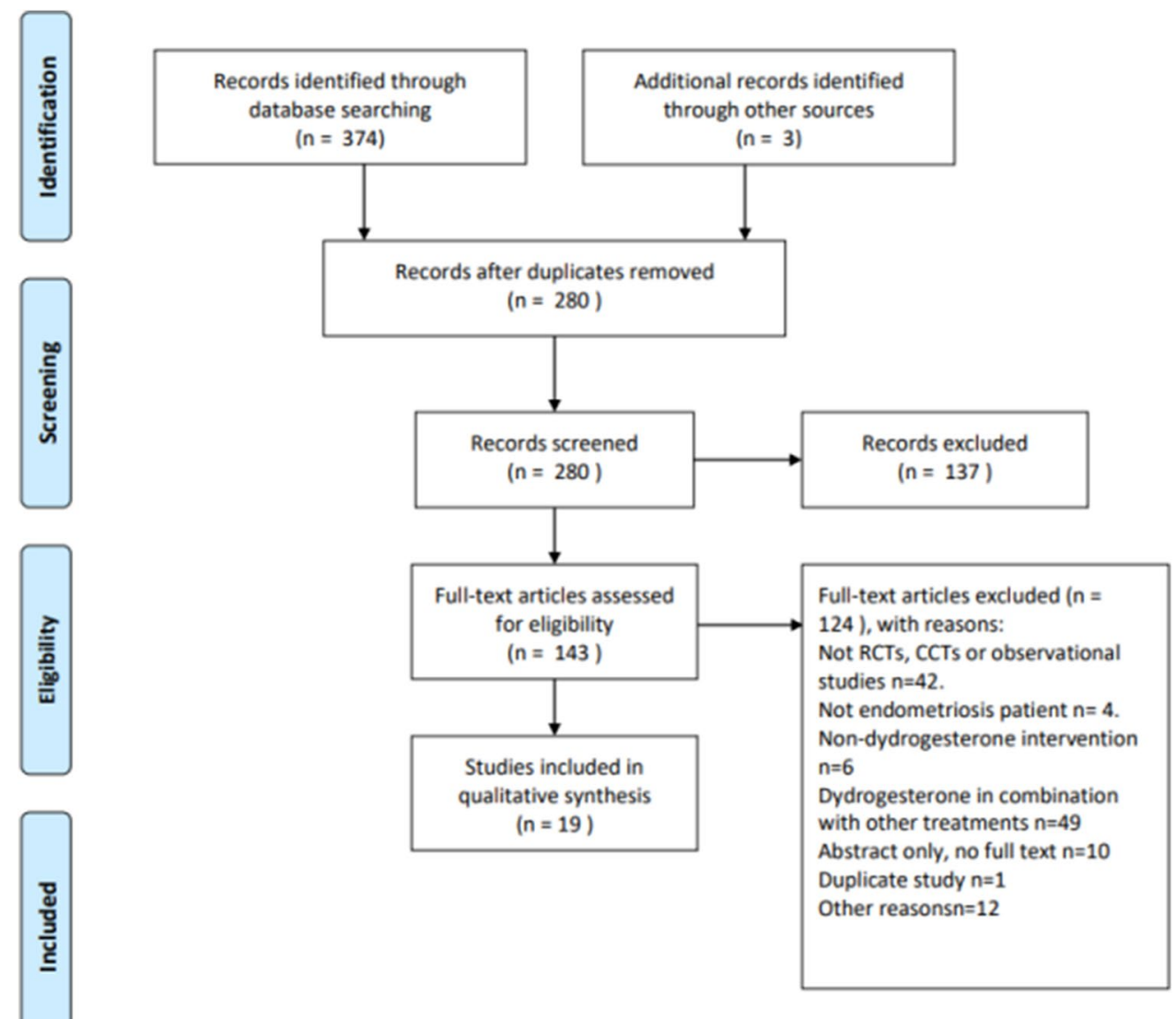

allocation concealment, blinding, study attrition, selective reporting, and other bias. We also provided an overall assessment of each study. We rated a trial low risk of bias when all risk of bias domains were assessed as low risk, moderate risk of bias when at least one domain was assessed as moderate with no high risk assessments, and high risk of bias when any domain was assessed as high risk.

The cohort study included was assessed using Newcastle-Ottawa Scale (NOS) for evaluating selection, comparability, and outcome.

Study assessments were performed by $\mathrm{CP}$ and $\mathrm{YH}$, and disagreements were resolved by discussion with assistance from a third party YFZ if necessary.

\section{Results}

\section{Mapping of included evidence}

The trial search identified 377 references, and 280 references remained after removing duplicates. A total of 137 citations were excluded after screening of the title and abstract. Subsequently, 124 articles were excluded following a full-text review, leaving 19 articles eligible for qualitative synthesis $[12,16,19-35]$. The study screening process and reasons for exclusion at the full-text screening stage are presented in Fig. 1.

\section{Summary of publication years}

The earliest included study was published in 1976. More than half of the included evidence were published from 2014 to 2019 (Fig. 2).

\section{Summary of studies}

In all, 19 studies [12, 16, 19-35] were included. Nine RCTs were identified that compared dydrogesterone with a different dosage of dydrogesterone or placebo (1 study [20] with 62 participants), gestrinone (7 studies [22, 24, 25, 27 , 28, 30, 32] with 693 participants), [20] or traditional Chinese medicine and acupuncture therapy (1 study ${ }^{[1} 2^{]}$with 64 participants). Four CCTs were identified that compared dydrogesterone with letrozole (1 study [26] with 90 participants), gestrinone (1 study [29] with 120 participants), GnRH-a leuprolide (1 study [31] with 80 participants), or coagulation of endometriotic foci, danazol, norcolut and depo-medroxyprogesterone acetate (1 study with 300 participants) [35]. One cohort study [33] was identified that compared dydrogesterone with no treatment after surgery 
Summary of publication years

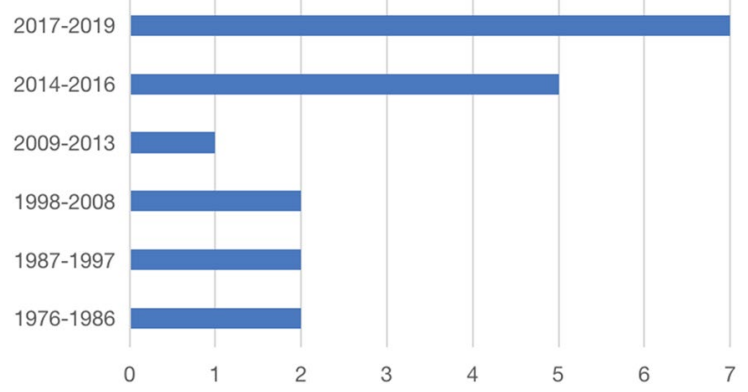

Fig. 2 Number of included studies by year of publication

(with 69 participants). The remaining 5 studies [16, 19, 21, 23,34 ] (with 231 participants) were single-arm studies that investigated dydrogesterone without comparisons.

Included studies originated from various regions. A majority of studies (63\%) were conducted in China, followed by Australia (5.3\%), United Kingdom (10.5\%), India (5.3\%), Russia (5.3\%), Belgium (5.3\%), and Uzbekistan (5.3\%). The number of patients in each study ranged from 18 to 130 , for a total of 1709 patients. Most of the studies were conducted in a single center (73.6\%), and most did not provide funding information $(89.5 \%)$ (Table 1).

\section{Summary of population characteristics}

Across the 19 included studies, the age of participants ranged from 18 to 51 years (mean age from 28.8 to 35.2 years). Twelve studies [12, 16, 19-21, 24-26, 31, 33-35] used pathological examination and surgery-culdoscopy, laparoscopy, and laparotomy - to diagnose endometriosis. Three studies $[20,21,33]$ used a diagnosis of endometriosis in line with the AFS classification, and one study [31] used a diagnosis in line with the Guide for Diagnosis and Treatment of Endometriosis. One study [29] used a mix of color Doppler ultrasound and surgery consistent with the criteria for diagnosing endometriosis presented in the journal Obstetrics and Gynecology published by the People's Health Publishing House. One study [32] used a mix of electrocoagulation, pathological examination, and surgery to diagnose endometriosis, while another study [12] used solely the diagnostic criteria put forth in the Clinical Diagnosis and Treatment Guide-Obstetrics and Gynecology Volume (People's Medical Publishing House, 2011). The remaining five studies [22, $23,27,28,30]$ did not provide information on the diagnostic criteria used.

\section{Summary of intervention in single-arm studies}

Five included single-arm studies [16, 19, 21, 23, 34] investigated various dosages of dydrogesterone and different treatment durations. Two studies [16, 21] prescribed 10-20$\mathrm{mg}$ dydrogesterone daily to patients according to the severity of endometriosis (40\%). The other three studies $[19,23$, 34] prescribed 20-30-mg or 20-60-mg dydrogesterone daily $(60 \%)$. Four studies $[16,19,21,34]$ reported various treatment durations, and one study [23] did not report treatment duration (Table 2).

\section{Summary of outcomes and findings in single-arm studies}

The outcomes and measurements or definitions of the assessments reported in the five single-arm studies [16, 19, 21, 23, 34] are presented in Table 2.

Overall, four studies $(80 \%)$ [19, 21, 23, 34] reported changes in pain relief. Three studies $(60 \%)$ measured the pregnancy rate $[16,19,21]$. All five studies $(100 \%)[16,19$, $21,23,34]$ measured clinical response. One study $(20 \%)$ [16] measured the recurrence rate [6]. Two studies (40\%) $[16,34]$ assessed improvement in endometriosis. Another two studies $(40 \%)[16,23]$ reported adverse events [6]. One study (20\%) [16] measured the appearance of uncharted lesions and the impediment to fertility [6], and one study (20\%) [34] measured the duration of the menstrual cycle. The key findings of the five single-arm studies are summarized in Table 2.

\section{Summary of intervention and comparators in RCTs and CCTs and the cohort study}

Nine RCTs [12, 20, 22, 24, 25, 27, 28, 30, 32], four CCTs $[26,29,31,34]$ and one cohort study [33] compared the effect of various dosages of dydrogesterone versus nondydrogesterone therapy (Table 3). One study [20] compared a low (40 mg/day)and high dosage $(60 \mathrm{mg} /$ day $)$ of dydrogesterone versus placebo. The remaining 13 studies $[12,22,24-34]$ compared dydrogesterone (10-20 mg/ day) with non-dydrogesterone therapies, namely gestrinone $(n=8)$, letrozole $(n=1), \mathrm{GnRH}-\mathrm{a}$ leuprolide acetate $(n=1)$, traditional Chinese medicine $(n=1)$, no treatment $(n=1)$, coagulation of endometriotic foci, danazol, norcolut and depo-medroxyprogesterone $(n=1)$. Of these 13 studies, 8 $[22,24,25,27-30,32]$ evaluated gestrinone, and participants were administered $2.5 \mathrm{mg}$ twice a week from day 1 of menstruation after surgery for a duration of 3 months $(n=4)$ [24, 29, 30, 32], 6 months $(n=1)$ [28], or 3-6 months $(n=3)$ $[22,25,27]$.

\section{Summary of outcome categories}

Outcomes reported in the 14 randomized, clinical controlled and cohort studies [12, 20, 22, 24-34] are presented in Table 3. 
Table 1 Mapping of general study characteristics (total $N$ of included records $=19$ )

\begin{tabular}{llll}
\hline Item & Variables & $N$ of studies & \% of studies \\
\hline Study design & RCT & 9 & 47.3 \\
& CCT & 4 & 21.1 \\
& Cohort & 1 & 5.3 \\
\multirow{5}{*}{ Region } & Single-arm study & 5 & 26.3 \\
& Australia & 1 & 5.3 \\
& United Kingdom & 2 & 10.5 \\
& Russia & 1 & 5.3 \\
& India & 1 & 5.3 \\
Sample size & Belgium & 1 & 5.3 \\
& China & 12 & 63 \\
Center & Uzbekistan & 1 & 5.3 \\
& Range & $14-300$ & - \\
& $\geq 100$ & 5 & 26.3 \\
& Single & 14 & 73.6 \\
Funding & Multi & 4 & 21.1 \\
& NR & 1 & 5.3 \\
& Industry & 0 & 0 \\
& Non-industry & 2 & 10.5 \\
& NR & 17 & 89.5 \\
\hline
\end{tabular}

Overall, nine studies (64.2\%) reported changes in pain relief. Ten studies $(71.4 \%)$ measured pregnancy rates. Nine studies $(64.2 \%)$ measured clinical response using various definitions. Five studies (35.7\%) measured the recurrence rate. Nine studies $(64.2 \%)$ measured adverse events. One study $(7.1 \%)$ evaluated improvement in endometriosis. One study (7.1\%) assessed menstrual function disorders. Only one study $(7.1 \%)$ measured menstrual recovery time. One study (7.1\%) assessed dyspareunia. One study (7.1\%) measured the number of miscarriages. Two studies (14.2\%) assessed allergic reactions or liver function damage, pelvic nodules, and the incidence of ovarian chocolate cysts.

\section{Summary of key findings in comparative studies}

Overton et al. [20] compared dydrogesterone (40 mg/day), dydrogesterone $(60 \mathrm{mg} /$ day $)$ with identical placebos and found that pain was significantly relieved after treatment with $60-\mathrm{mg}$ dydrogesterone for 6 months. Furthermore, this improvement was still evident at the 12-month follow-up. No differences were identified in the change in pain score with $40 \mathrm{mg}$ of dydrogesterone compared with placebo (OR 0.80 , 95\% CI 0.27-2.37). There was no significant improvement in objective efficacy (AFS scores) at 6 months with dydrogesterone (40 mg and $60 \mathrm{mg}$ ) compared with placebo (OR $0.53,95 \%$ CI 0.14-1.94). Even though a higher number of pregnancies was observed in the dydrogesterone group than in the placebo group (10/43 versus $3 / 19$ at 6 months, 18/37 versus $7 / 19$ at 12 months), this difference was not statistically significant. However, because of the wide confidence intervals, the data should be interpreted with caution [36].

Eight studies [22, 24, 27-30, 32] compared dydrogesterone versus gestrinone. Compared with the gestrinone group, patients treated with dydrogesterone had statistically lower VAS of dysmenorrhea after treatment for 12 months (Fig. 3). There was no significant difference between the groups in the occurrence of dysmenorrhea at 3 and 6 months (Fig. 3, or pelvic pain and dyspareunia 3, 6 and 12 months after treatment (Fig. 4, 5). Moderate heterogeneity $\left(I^{2}=71 \%, \mathrm{p}=0.03\right.$ and $I^{2}=63 \%, \mathrm{p}=0.07$, respectively) was observed for pelvic pain and dyspareunia at 3 months, which was caused by the Luo 2017 study. This was probably due to the use of a smaller dose $(10 \mathrm{mg}$ versus $10-20 \mathrm{mg}$ ) and the shorter duration (3 month versus 3-6 months) of dydrogesterone use. After treatment, patients treated with dydrogesterone had much higher pregnancy rates than those receiving gestrinone (Fig. 6). No significant difference was found in the recurrence rate of endometriosis between the groups (Fig. 7). In addition, the rate of adverse events (elevated transaminase levels, vaginal dryness, and acne) was significantly lower in the patients treated with dydrogesterone than gestrinone (Fig. 8). Two studies [24, 32] in which clinical improvement of endometriosis were defined reported no difference between dydrogesterone and gestrinone treatment (Fig. 9).

One study compared dydrogesterone with GnRH-a leuprolide acetate [31], letrozole [26], traditional Chinese medicine [12], and no treatment [33]. The results are presented in Table 4. The study [33] comparing dydrogesterone with no treatment showed a favorable pregnancy rate in the dydrogesterone group after treatment, with a statistically significant improvement noted 6 months after treatment.

One study compared dydrogesterone $(10 \mathrm{mg} /$ day, $\mathrm{n}=60)$ versus coagulation of endometriotic foci (during laparoscopy, $\mathrm{n}=60$ ), danazol (400 mg twice/day, $\mathrm{n}=30$ ), norcolut $(10 \mathrm{mg} /$ day, $\mathrm{n}=60)$ and depo-medroxyprogesterone $(50 \mathrm{mg} /$ week, $n=60)^{\left[35^{]}\right.}$. Danazol and dydrogesterone were the two most effective agents following surgical treatment in terms of the presence of pain, the restoration of a two-phase menstrual cycle, and the occurrence of pregnancy. However, no statistical inference was made in this study ${ }^{\left[35^{]}\right.}$.

\section{Summary of validity of RCT and CCT studies}

The validity of studies was assessed for RCTs and CCTs using the Cochrane review standard-risk of bias assessment (Fig. 10). 


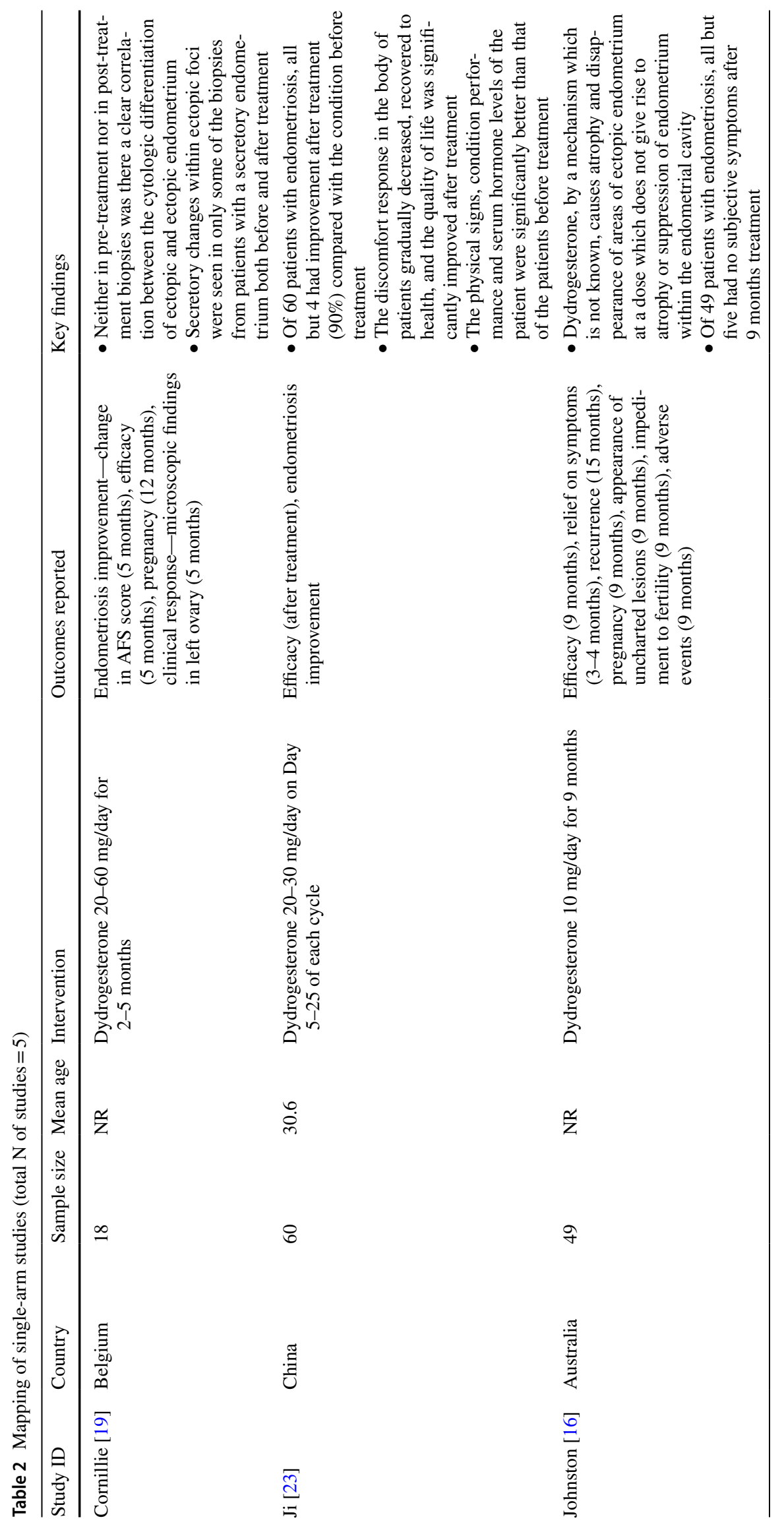




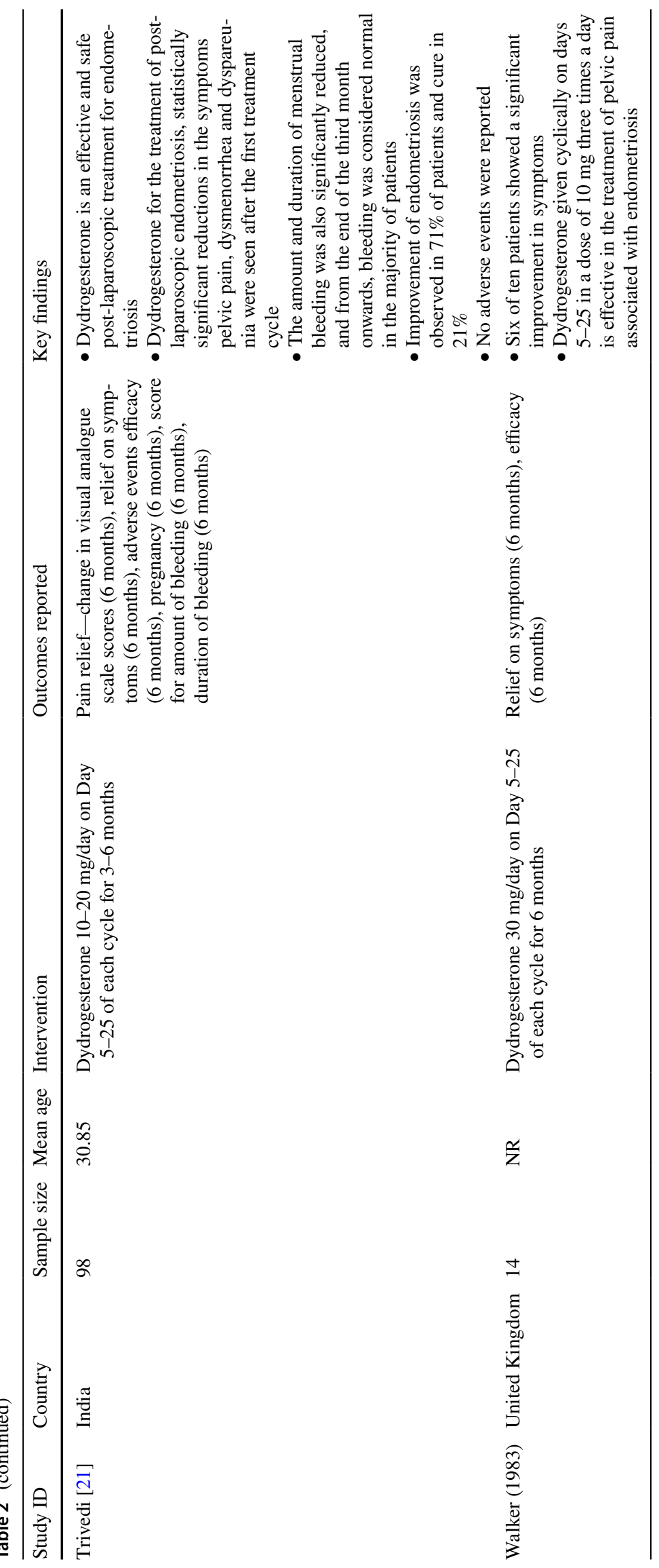




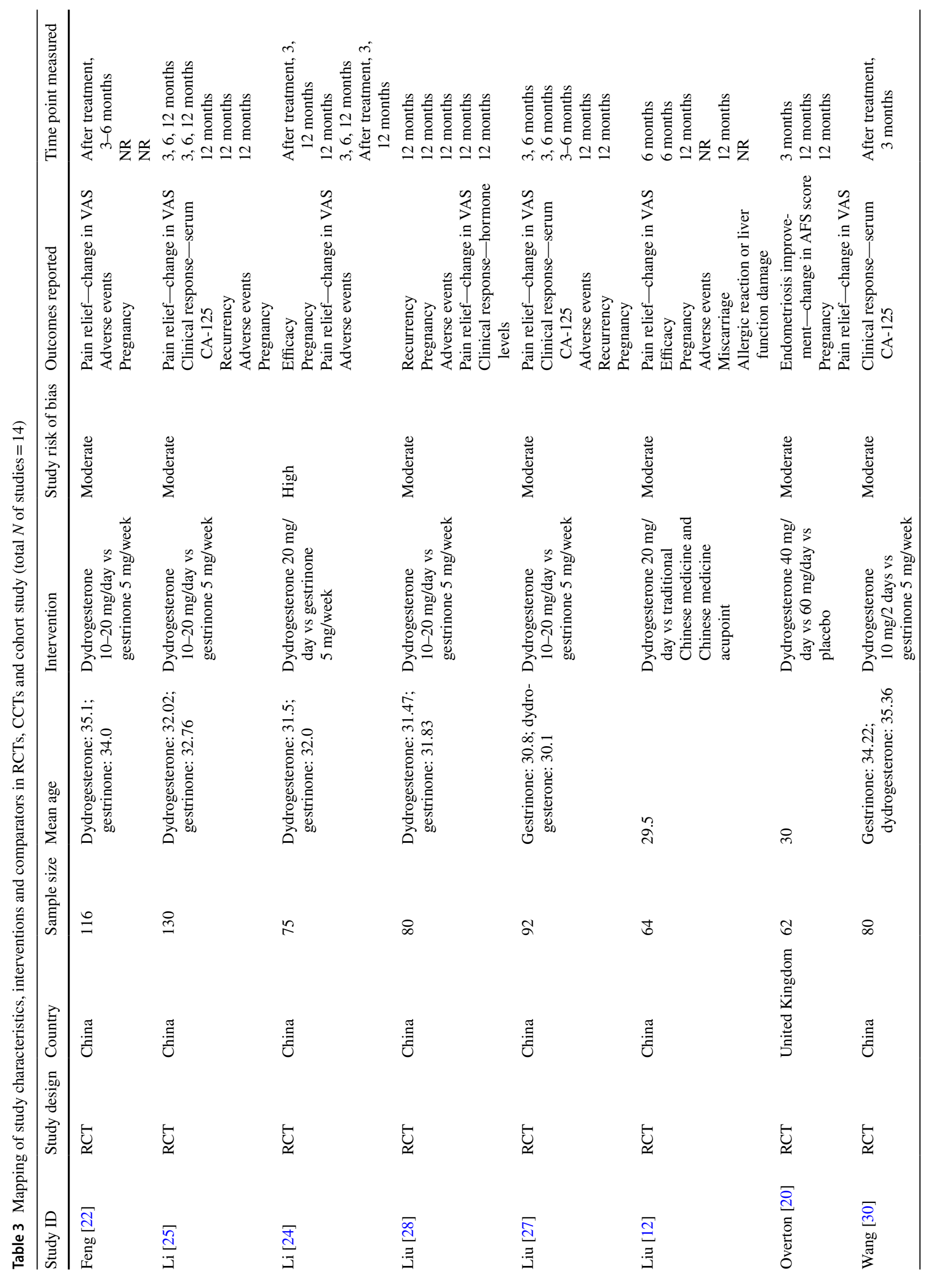




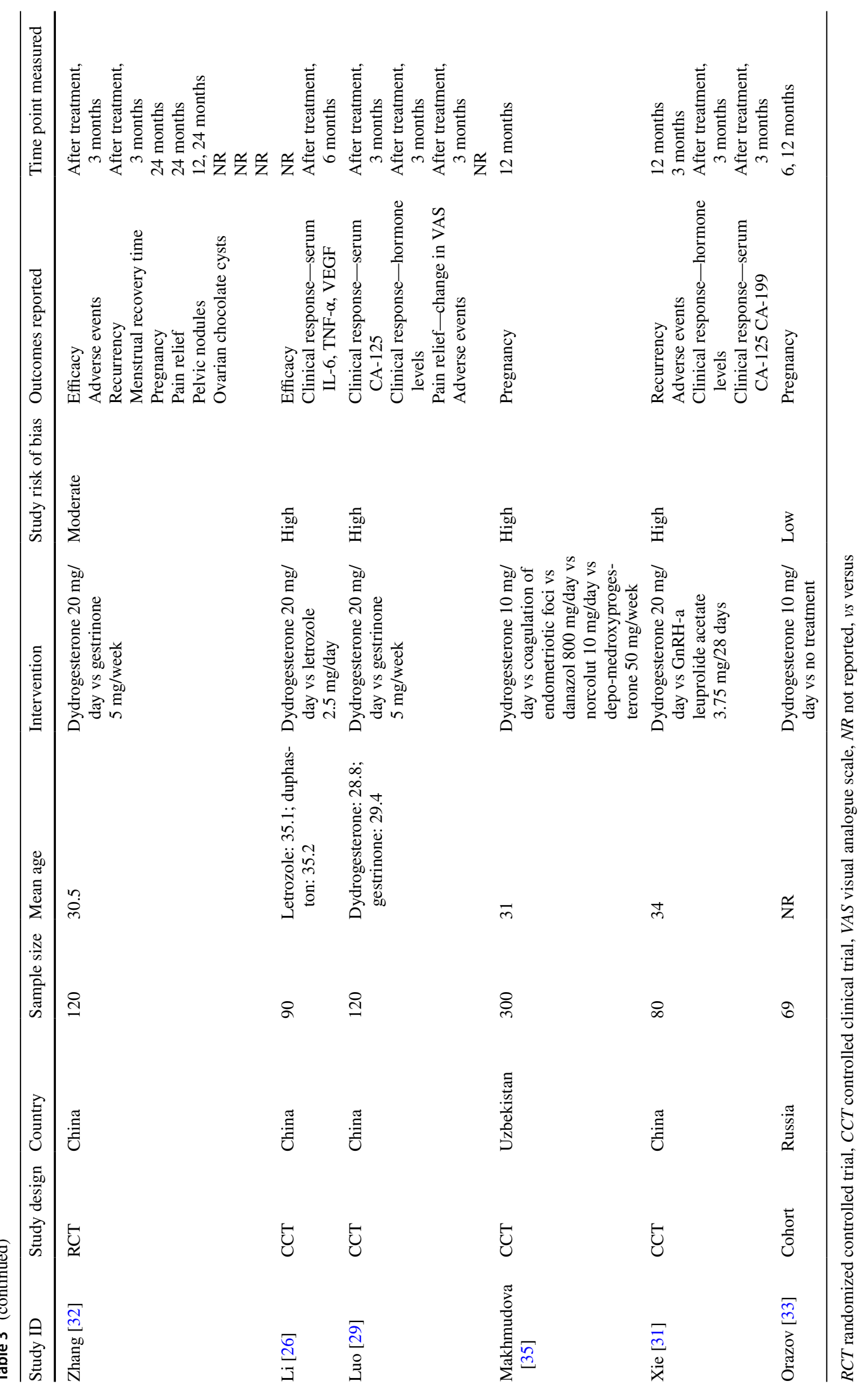




\section{Selection bias}

In terms of random sequence generation and allocation concealment, only two studies were rated as low risk of selection bias by reporting a computer-generated randomization method. Four CCTs and one RCT were rated as high risk of selection bias. The remaining six studies were rated as unclear risk of bias because no randomization details were provided.

\section{Performance bias}

All 13 studies were rated as unclear risk of bias since no details about the blinding of participants and personnel were reported.

\section{Detection bias}

All 13 studies were rated as unclear risk of bias since no details about the blinding of the outcome assessment was reported.

\section{Attrition bias}

One study did not report withdrawals (through there may have been no withdrawals). The remaining 12 studies were rated as low risk of bias. Eleven studies of these 12 studies reported no withdraw during treatment and 1 of these 12 studies reported less than $10 \%$ drop-out rate.

\section{Reporting bias}

One study did not define the outcome clearly. The remaining 12 studies were rated as low risk of bias because all predefined outcomes were reported in the results.

\section{Other bias}

All 13 studies were rated as unclear risk of bias. Twelve studies did not report funding information, and 1 study reported non-industry funding.

\section{Validity of cohort study}

Using the NOS assessment tool, a quality assessment of the included observational cohort study resulted in a score of 6 ( 2 points for selection, 1 point for comparability, and 2 points for outcome) which was consistent with a low risk of bias. Details of the assessment items in the domains for the included article are listed in Table 5.

\section{Discussion}

We evaluated five single-arm studies that investigated various dosages of dydrogesterone and different treatment durations, and nine RCTs, four CCTs and one cohort study that compared the effect of various dosages of dydrogesterone with non-dydrogesterone therapies. This evidence mapping

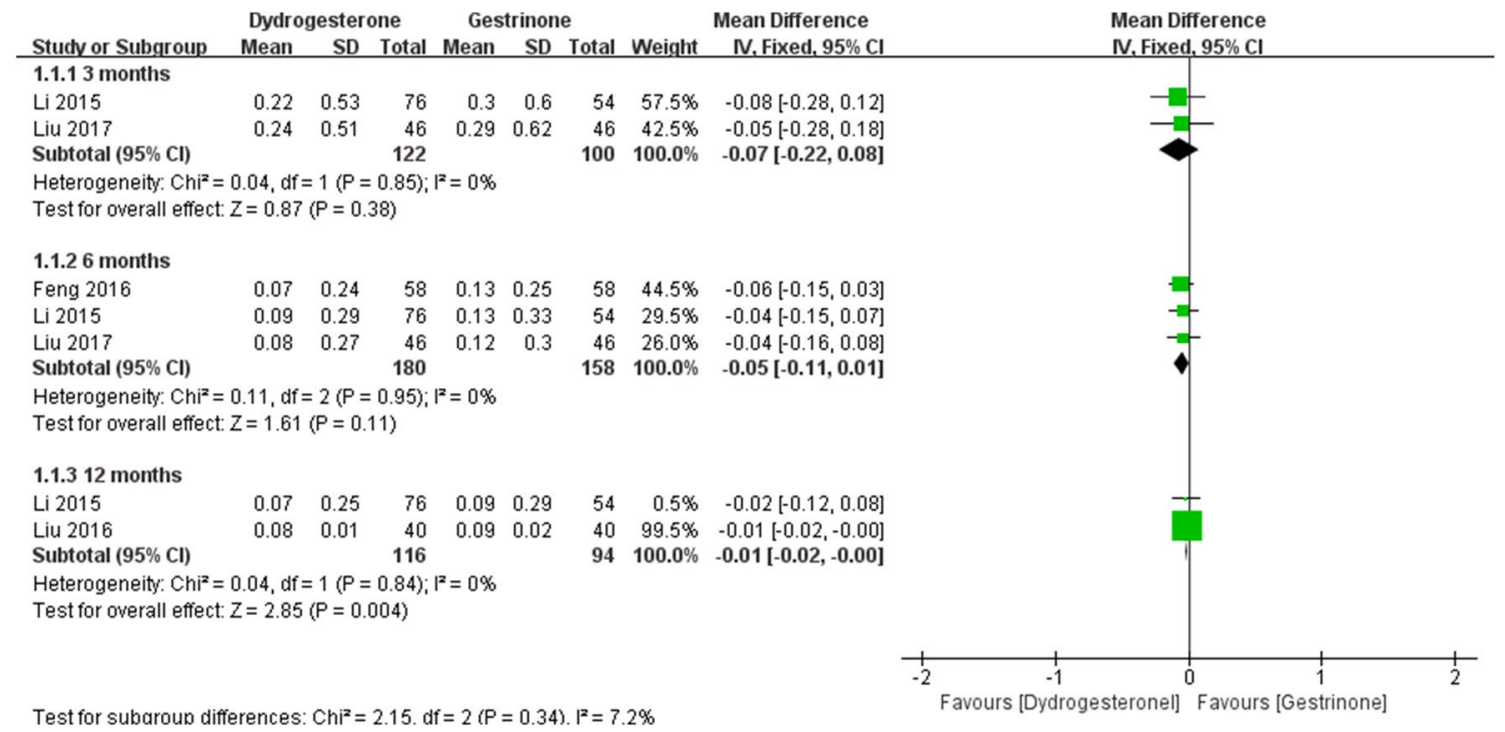

Fig. 3 Meta-analysis of dysmenorrhea: dydrogesterone versus gestrinone 


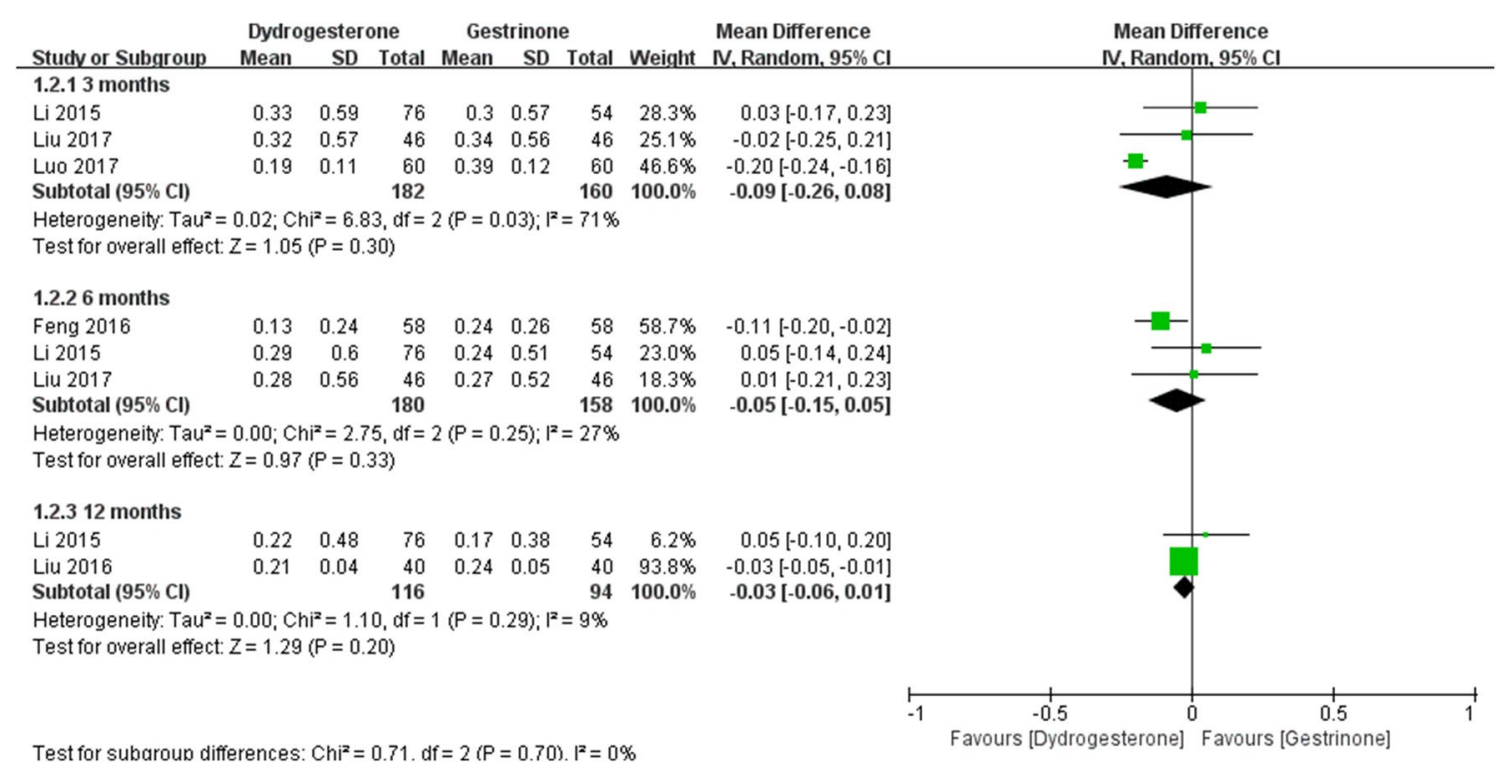

Fig. 4 Meta-analysis of pelvic pain: dydrogesterone versus gestrinone

included 1709 female participants. All the participants had a diagnosis of endometriosis. Dydrogesterone was found to be more effective than gestrinone in relieving dysmenorrhea and achieving a higher pregnancy rate and was associated with a lower risk of adverse events such as elevated transaminase levels, vaginal dryness, and acne. Compared with GnRH-a, dydrogesterone was also associated with a lower risk of endometriosis recurrence and elevated transaminase levels. Whether there is a difference between dydrogesterone and leuprolide acetate, letrozole, and traditional Chinese medicine remains unclear due to insufficient data.

The above findings may be impacted by attrition bias and selective reporting in individual RCTs [35]. The randomization and blinding of outcome assessments were inadequately described in the original RCTs, which induced selection and detection bias. This bias also affected the quality of the metaanalyses. In addition, small sample sizes and unexplainable heterogeneity between studies also impacted the quality of

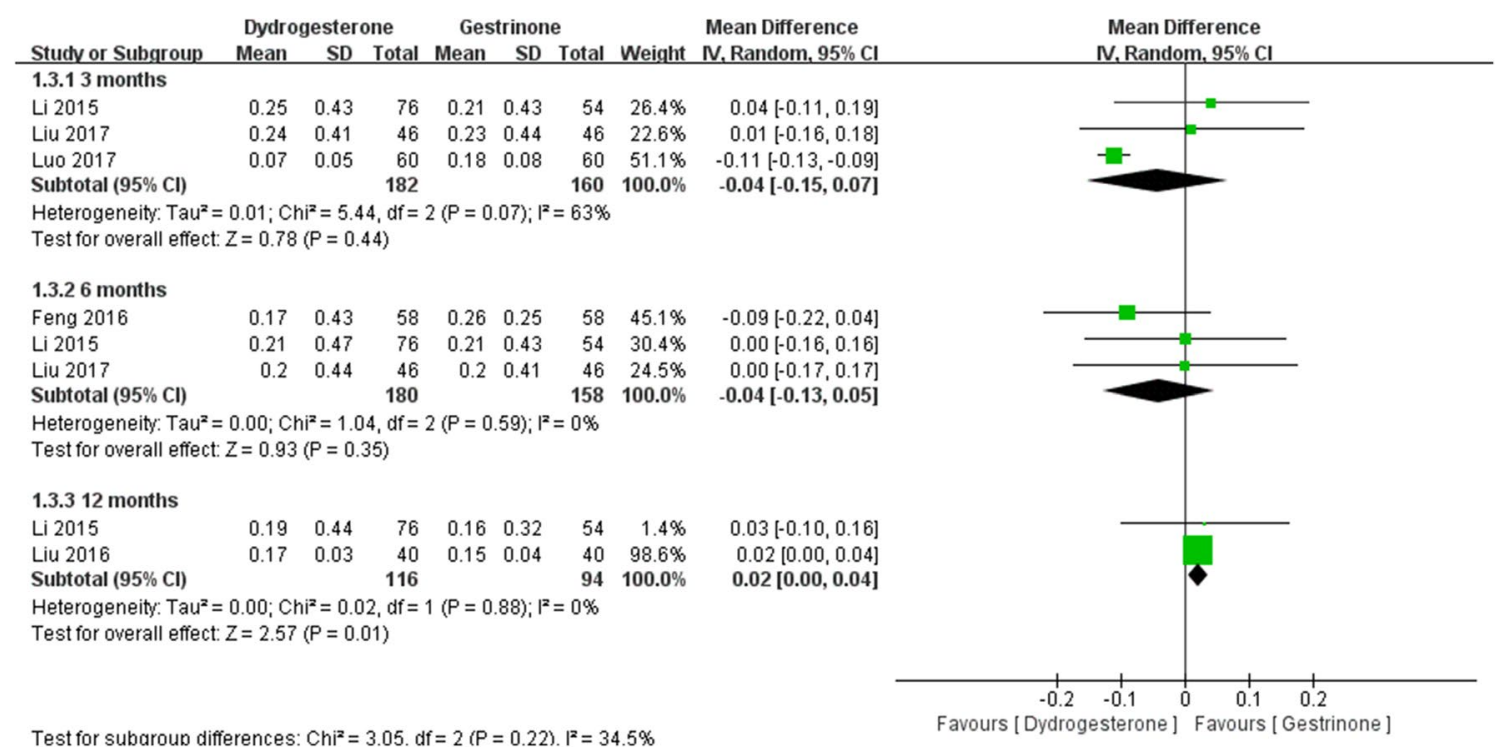

Fig. 5 Meta-analysis of dyspareunia: dydrogesterone versus gestrinone 


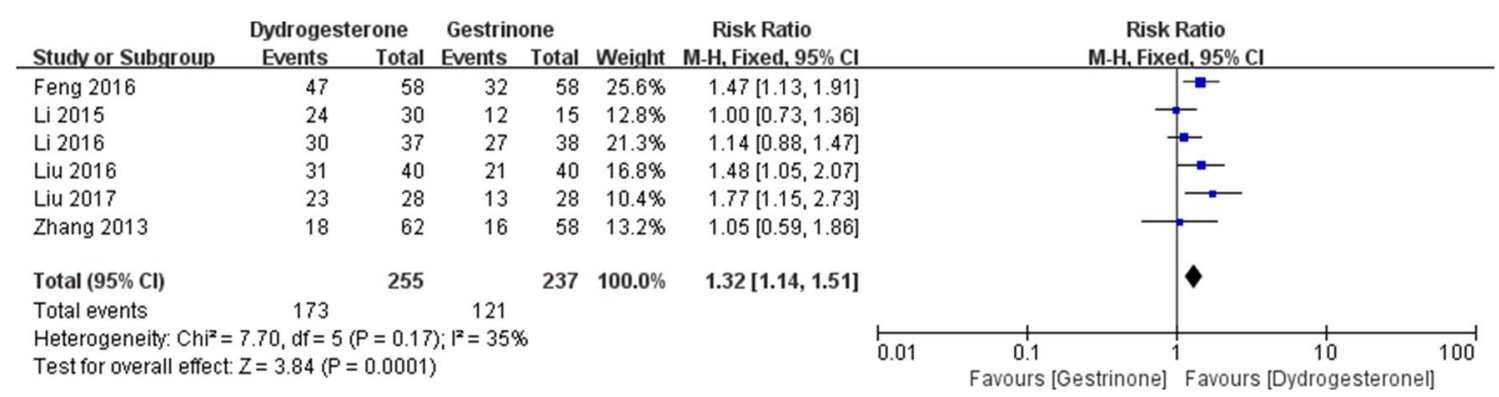

Fig. 6 Meta-analysis of pregnancy rate: dydrogesterone versus gestrinone

the body of evidence, especially for outcomes such as pain relief, pregnancy rate, and adverse events. Certain included studies used the visual analogue score (VAS), while others used American Fertility Society (AFS) scores to measure improvement in endometriosis which is reflected in these outcomes. Owing to the shortcomings of the current VAS or AFS scores which are primarily descriptive classifications unrelated to biologic function, these measures may be inadequate to accurately assess improvement in endometriosis, especially long-term improvement.

There is very limited evidence for the effectiveness and safety of these drugs in the treatment of endometriosis due to the limited number of randomized controlled trials comparing each drug. However, a number of published clinical studies have provided evidence relevant to the pharmacological treatment of endometriosis. Synthetic progestogens have been shown to reduce AFS scores and provide pain relief, but the treatment does not improve fertility in women of reproductive age [37, 38]. There are only a few controlled clinical trials of dydrogesterone for the treatment of endometriosis which have shown symptomatic improvement with some evidence of objective improvement [16, 19]. Currently, guidelines for the management and diagnosis of endometriosis developed and funded by National Institute for Health and Care Excellence recommend the use of a combination oral contraceptive pill or a progestogen for women with suspected, confirmed, or recurrent endometriosis [10]. The
European Society of Human Reproduction and Embryology (ESHRE) guidelines recommended progestagens or antiprogestagens (gestrinone) as one option to reduce endometriosis-associated pain (GRADE A). ESHRE guidelines also recommend the use of GnRH agonists (nafarelin, leuprolide, buserelin, goserelin or triptorelin) as an option for reducing endometriosis-associated pain, although evidence is limited regarding dosage and duration of treatment (GRADE A) [1].

Compared with gestrinone, GnRH agonists, and no treatment, dydrogesterone may be more effective in treating endometriosis. First, it does not suppress the normal endometrium or alter the natural progression of endometriosis, while causing atrophy of ectopic endometrium [20]. Second, most of the available evidence indicates that dydrogesterone does not inhibit ovulation and regular menstruation at the usual therapeutic dosages. Hence, patients are able to conceive while using dydrogesterone, if they so desire. Furthermore, dydrogesterone has not been shown to adversely affect embryos. Finally, dydrogesterone-associated side effects are rare as it has relatively low antagonistic activity at glucocorticoid and mineralocorticoid receptors compared with progesterone [14]. Consequently, weight gain and edema are not observed with dydrogesterone.

When investigating the effectiveness of progestogens and anti-progestogens in the treatment of painful endometriosis, Brown et al. compared dydrogesterone with placebo and found no evidence of a difference in objective efficacy [36].

\begin{tabular}{|c|c|c|c|c|c|}
\hline \multirow[b]{2}{*}{ Study or Subgroup } & \multicolumn{2}{|c|}{ Dydrogesterone } & \multicolumn{2}{|c|}{ Gestrinone } & \multirow[b]{2}{*}{ Weight } \\
\hline & Events & Total & Events & Total & \\
\hline Li 2015 & 9 & 76 & 7 & 54 & $30.0 \%$ \\
\hline Li 2016 & 4 & 37 & 5 & 38 & $18.1 \%$ \\
\hline Liu 2016 & 4 & 40 & 5 & 40 & $18.3 \%$ \\
\hline Liu 2017 & 2 & 46 & 3 & 46 & $11.0 \%$ \\
\hline Zhang 2013 & 8 & 62 & 6 & 58 & $22.7 \%$ \\
\hline Total $(95 \% \mathrm{Cl})$ & \multicolumn{3}{|c|}{261} & 236 & \multirow[t]{2}{*}{$100.0 \%$} \\
\hline Total events & 27 & & 26 & & \\
\hline \multicolumn{6}{|c|}{$\begin{array}{l}\text { Heterogeneity: } \mathrm{Chi}^{2}=0.57, \mathrm{df}=4(P=0.97) ;\left.\right|^{2}=0 \% \\
\text { Test for overall effect: } Z=0.30(P=0.76)\end{array}$} \\
\hline
\end{tabular}

Risk Ratio Risk Ratio M-H, Fixed, 95\% Cl

$0.91[0.36,2.30]$

$0.82[0.24,2.82]$

$0.80[0.23,2.76]$

$0.67[0.12,3.81]$

$1.25[0.46,3.38]$

$0.92[0.56,1.54]$ M-H, Fixed, $95 \% \mathrm{Cl}$

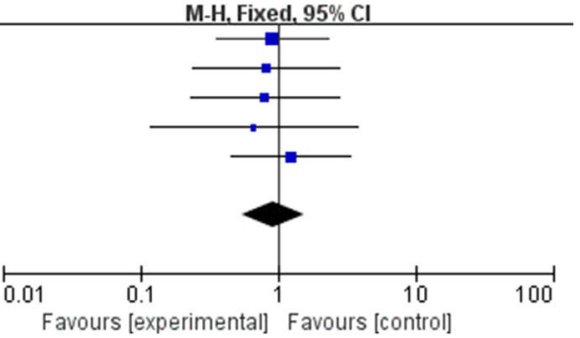

Fig. 7 Meta-analysis of recurrence: dydrogesterone versus gestrinone 


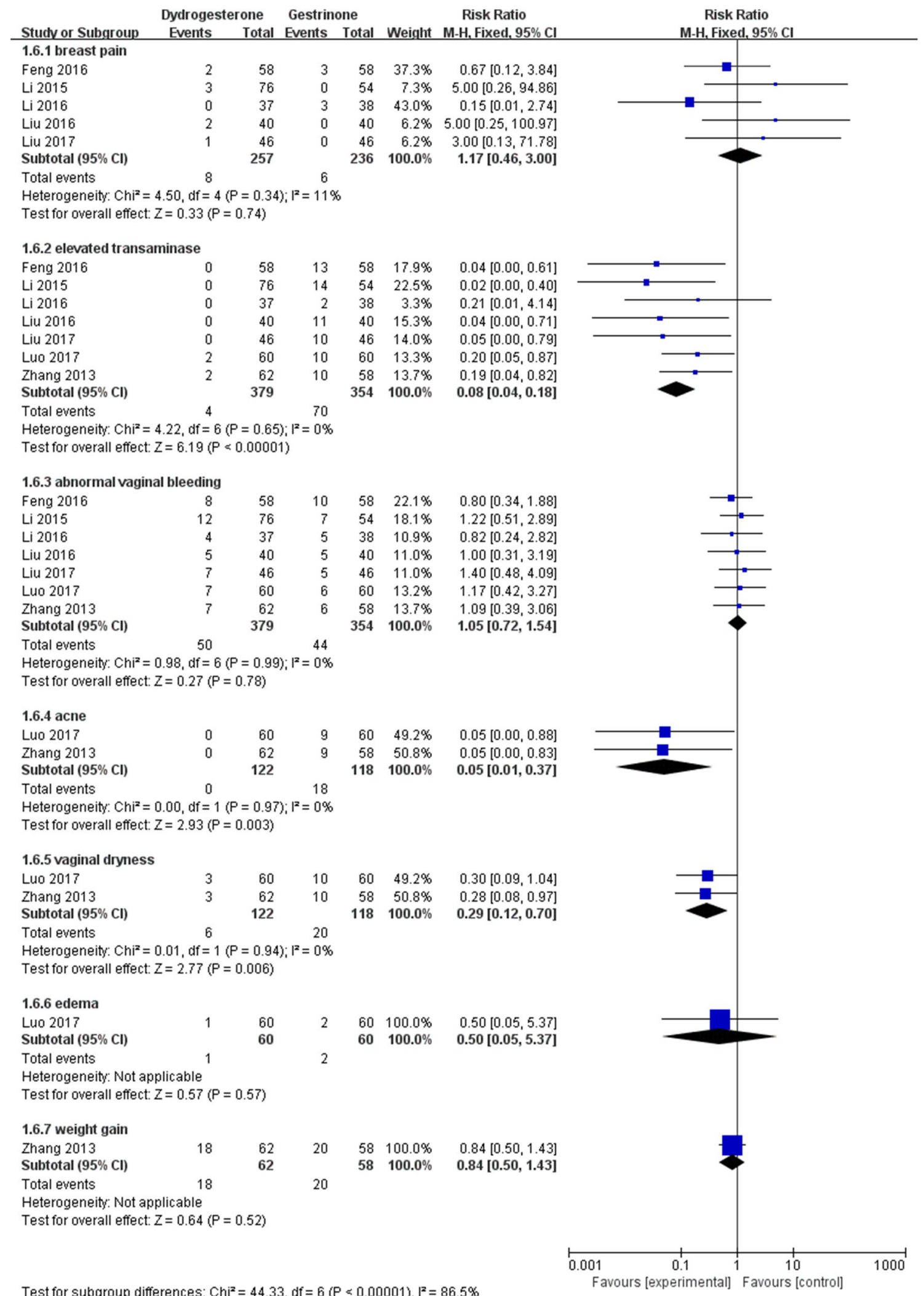

Fig. 8 Meta-analysis of adverse events: dydrogesterone versus gestrinone 


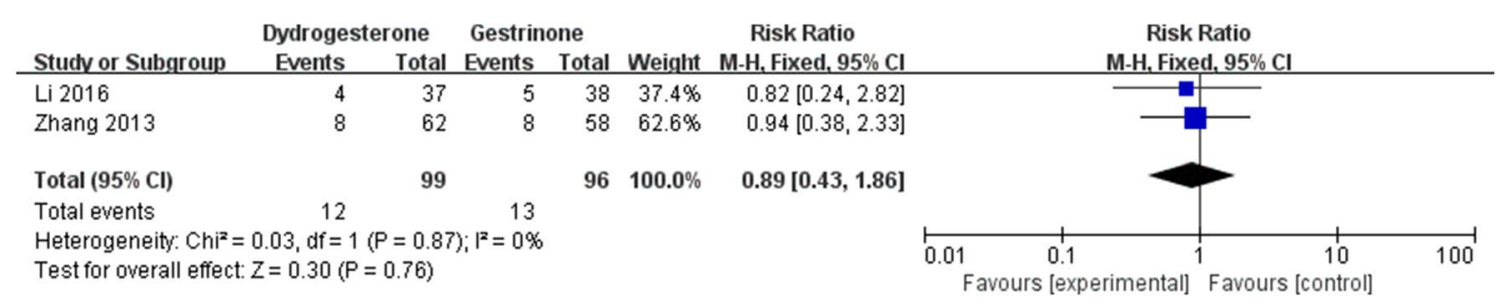

Fig. 9 Meta-analysis of no clinical response: dydrogesterone versus gestrinone

Table 4 Mapping of RCTs, CCTs and cohort study key findings (total $N$ of studies $=14$ )

\begin{tabular}{|c|c|c|c|c|c|c|}
\hline Outcomes & Definitions & $\begin{array}{l}\text { Time point of } \\
\text { measurement }\end{array}$ & $\begin{array}{l}\text { Significant difference } \\
\mathrm{RR}[95 \% \mathrm{CI}] / p \text { value }\end{array}$ & Favor of & $\begin{array}{l}N \text { of } \\
\text { partici- } \\
\text { pants }\end{array}$ & $N(\%)$ of studies \\
\hline \multicolumn{7}{|c|}{ Comparison 1: dydrogesterone (40 mg/day) versus dydrogesterone (60 mg/day) } \\
\hline \multirow[t]{2}{*}{ Changes in pain relief } & - & 6 months & $p=0.044$ & $\begin{array}{l}\text { Decrease of pain score } \\
\text { in } 60 \mathrm{mg} \text { dydrogester- } \\
\text { one group }\end{array}$ & 43 & $1(7.1)$ \\
\hline & & 12 months & $p=0.41$ & NS & 43 & $1(7.1)$ \\
\hline \multirow[t]{2}{*}{ Pregnancy rate } & - & 6 months & RR $0.77[0.25,2.34]$ & NS & 43 & $1(7.1)$ \\
\hline & & 12 months & RR $1.05[0.54,2.04]$ & NS & 43 & $1(7.1)$ \\
\hline $\begin{array}{l}\text { Endometriosis improve- } \\
\text { ment }\end{array}$ & AFS & 3 months & OR $0.53[0.14,1.94]$ & NS & 43 & $1(7.1)$ \\
\hline \multicolumn{7}{|c|}{ Comparison 2: dydrogesterone versus gestrinone (results are presented in Figs. 2, 3, 4, 5,6, 9, 10) } \\
\hline \multicolumn{7}{|c|}{ Comparison 3: dydrogesterone versus letrozole } \\
\hline Efficacy & Total $=$ no improvements & & RR $0.38[0.11,1.32]$ & NS & 90 & $1(7.1)$ \\
\hline \multicolumn{7}{|c|}{ Comparison 4: dydrogesterone versus GnRH-a leuprolide acetate } \\
\hline Recurrence & - & - & RR $0.13[0.02,0.95]$ & $\begin{array}{l}\text { Lower risk of recur- } \\
\text { rence in dydrogester- } \\
\text { one group }\end{array}$ & 80 & $1(7.1)$ \\
\hline \multirow[t]{3}{*}{ Adverse events } & Breast pain & & RR $1.00[0.06,15.44]$ & NS & 80 & $1(7.1)$ \\
\hline & Elevated transaminase & & RR $0.05[0.00,0.87]$ & $\begin{array}{l}\text { Lower risk of elevated } \\
\text { transaminase in } \\
\text { dydrogesterone group }\end{array}$ & 80 & $1(7.1)$ \\
\hline & Abnormal vaginal bleedin & & RR $0.80[0.23,2.76]$ & NS & 80 & $1(7.1)$ \\
\hline \multicolumn{7}{|c|}{ Comparison 5: dydrogesterone versus traditional Chinese medicine and acupoint } \\
\hline $\begin{array}{l}\text { Changes in pain relief- } \\
\text { dysmenorrhea }\end{array}$ & VAS & 6 months & 0.1 & NS & 64 & $1(7.1)$ \\
\hline Pregnancy rate & - & 12 months & RR $0.92[0.54,1.58]$ & NS & 64 & $1(7.1)$ \\
\hline Miscarriage & - & 12 months & RR $1.13[0.07,17.34]$ & NS & 64 & $1(7.1)$ \\
\hline Efficacy & Total $=$ no improvements & & RR $1.26[0.59,2.68]$ & NS & 64 & $1(7.1)$ \\
\hline \multicolumn{7}{|c|}{ Comparison 6: dydrogesterone versus no treatment } \\
\hline \multirow[t]{2}{*}{ Pregnancy rate } & - & 6 months & RR $1.58[0.75,3.32]$ & NS & 69 & $1(7.1)$ \\
\hline & - & 12 months & RR $1.55[1.00,2.41]$ & $\begin{array}{l}\text { In favor of dydroges- } \\
\text { terone }\end{array}$ & 69 & $1(7.1)$ \\
\hline
\end{tabular}

NS no statistically significant difference 
Table 5 Newcastle-Ottawa quality assessment scale of cohort study

\begin{tabular}{|c|c|c|c|c|c|c|c|c|c|}
\hline \multirow[t]{2}{*}{ Study ID } & \multicolumn{4}{|l|}{ Selection } & \multirow{2}{*}{$\begin{array}{l}\text { Comparabil- } \\
\text { ity } \\
\text { Comparabil- } \\
\text { ity of cohorts }\end{array}$} & \multicolumn{3}{|l|}{ Outcome } & \multirow[t]{2}{*}{ Scores } \\
\hline & $\begin{array}{l}\text { Representa- } \\
\text { tiveness of } \\
\text { exposed } \\
\text { cohort }\end{array}$ & $\begin{array}{l}\text { Selection of } \\
\text { non-exposed } \\
\text { cohort }\end{array}$ & $\begin{array}{l}\text { Ascertain- } \\
\text { ment of } \\
\text { exposure }\end{array}$ & $\begin{array}{l}\text { Outcome pre- } \\
\text { sent at start } \\
\text { of study }\end{array}$ & & $\begin{array}{l}\text { Assessment } \\
\text { of outcome }\end{array}$ & $\begin{array}{l}\text { Length of } \\
\text { follow-up }\end{array}$ & $\begin{array}{l}\text { Adequacy of } \\
\text { follow-up }\end{array}$ & \\
\hline Orazov [33] & NA & NA & $*$ & $*$ & $*$ & $*$ & $*$ & $*$ & 6 \\
\hline
\end{tabular}

In contrast, Trivedi et al. found that pelvic pain, dysmenorrhea, and dyspareunia improved significantly after the first cycle of treatment with dydrogesterone in post-laparoscopic treatment of endometriosis [21].

At present, gestrinone is the only anti-progestagen that has been evaluated for the treatment of endometriosis. We did not identify any placebo-controlled trials or therapy trials comparing the efficacy of gestrinone. Only one review compared gestrinone with danazol [35] or a GnRH analogue (leuprorelin) [31] and found no evidence supporting a benefit of gestrinone over danazol. However, compared with

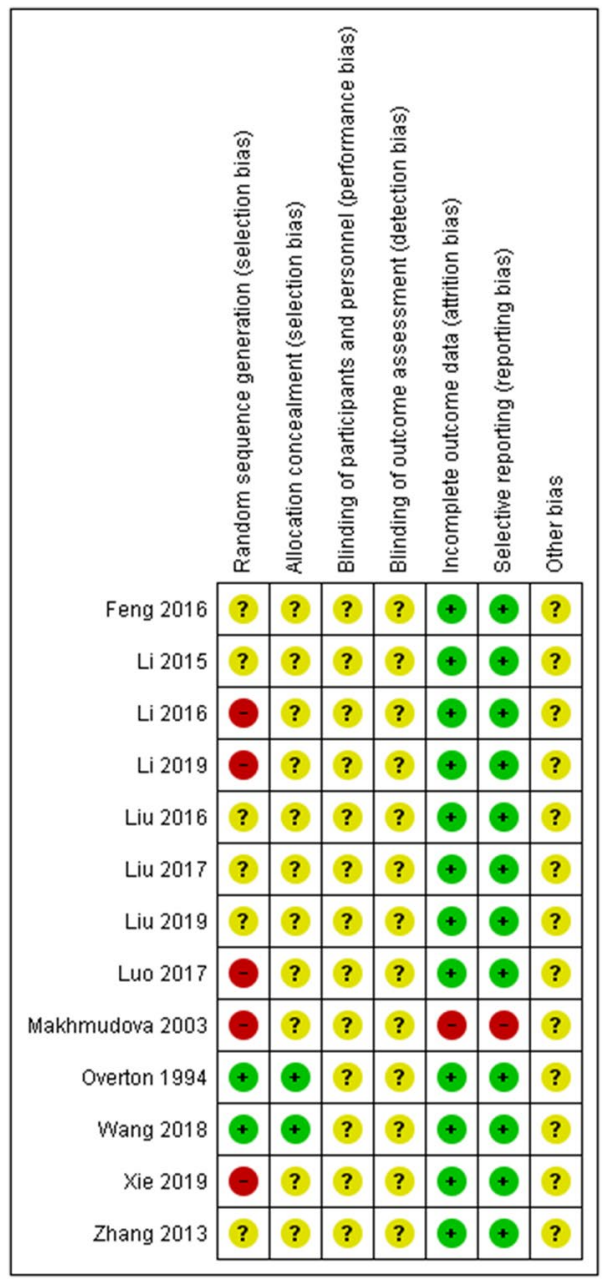

Fig. 10 Mapping of RCT and CCT validity gestrinone, a GnRH analogue (leuprorelin) significantly improved dysmenorrhea [31]. In this evidence mapping, dydrogesterone significantly improved pelvic pain and dysmenorrhea and lowered the occurrence of adverse events (elevated transaminase levels, vaginal dryness, and acne).

GnRH agonists, potentially useful for treating extensive endometriosis, function by rendering the patient hypoestrogenic thereby generating a condition of pseudomenopause. The pregnancy rate following treatment with GnRH agonists is not significantly different than that observed with 'watchful waiting' [39]. The major side effects of GnRH agonists are hot flushes, vaginal dryness, headaches, superficial dyspareunia, and a potential for the development of osteoporotic changes [15]. Furthermore, patients are not able to conceive while using GnRH agonists. Due to small sample sizes, we were unable to evaluate the differences between dydrogesterone and $\mathrm{GnRH}$ agonist treatment of endometriosis.

This study has a number of strengths. First, the search strategy was developed by professional information specialists who searched both electronic databases and the references of relevant systematic reviews, allowing the identification of a maximum number of relevant RCTs and CCTs. Second, the study screening and data extraction process were conducted by two researchers independently to minimize bias. Like all other studies, our evidence mapping also has some limitations. For instance, most of the included studies were published in journals with a lower impact factor, and there were some limitations in the design of these clinical studies. Specifically, the dose of dydrogesterone, the duration of therapy, and the criteria used to evaluate improvement of endometriosis were not consistent across the included studies. Consequently, primary and secondary outcomes' data were insufficient to detect a clear difference between the groups. Wide confidence intervals were also noted for some results, and these data should be interpreted with caution [36]. Due to insufficient data, we failed to detect a difference between dydrogesterone and treatments with GnRH-a leuprolide acetate, letrozole, traditional Chinese medicine and acupuncture, or identical placebo.

Some further issues that were not discussed in this review should also be addressed in future studies. Although peritoneal superficial lesions and ovarian endometriomas represent the majority of endometriotic implants within the pelvis, 
deep infiltrating endometriosis and extra-pelvic endometriosis are the most challenging conditions to manage. Sometimes, medical therapy is sufficient to reduce symptoms [40]. However, a large number of patients may require an approach that entails complete eradication with a nerve and vascular sparing [41] to restore the normal pelvic anatomy and its functions.

\section{Conclusion}

\section{Implication for practice}

Dydrogesterone may be more effective in relieving pelvic pain and dysmenorrhea than gestrinone and appears to have fewer adverse effects. It may also be much safer to conceive while taking dydrogesterone. GnRH agonists have major side effects such as hot flushes, vaginal dryness, headaches, superficial dyspareunia, and a potential for the development of osteoporotic changes. Furthermore, conception should not be attempted while using this therapy. Compared to no treatment, dydrogesterone increases pregnancy rates during the first year after surgery, an increase with reaches statistical significance at 12 months.

\section{Implication for research}

At present, there is limited high-quality research investigating commonly used treatments for endometriosis and comparing dydrogesterone with other hormonal treatments. In designing future trials, care should be taken to apply uniform standards for evaluating improvements in endometriosis and to ensure that all valuable and pertinent data are included, such as the results of surgical treatments (and other confounders) at the time of diagnosis and entry into the study.

\section{Conclusion}

The amount and quality of evidence investigating the effects of dydrogesterone in the treatment of endometriosis is generally very low. Based on limited evidence, it is concluded that dydrogesterone may have some advantages over gestrinone,
GnRH agonists, and other therapeutic interventions in the treatment endometriosis. However, this conclusion should be viewed with caution. The findings from this evidence mapping and meta-analysis could be of major importance for healthcare providers and researchers.

Acknowledgements Chao Peng contributed to screening, coding of included articles, data analysis and drafted the manuscript, Yan Huang participated in screening, coding of included articles, data summary and helped draft the manuscript, Yingfang Zhou provided advice, data analysis and helped draft the manuscript. All the authors read and approved the final manuscript. The collection and assembly of data and editorial assistance were also provided by Miss Sai Zhao and Wenjie Chi from Systematic Review Solutions, Ltd. We thank Margueritte M. White M.D. of GlobalCommunityWriter for her editorial assistance and language editing and all other contributors who provided assistance and support but have not been mentioned here.

Author contributions CP: screening, coding of included articles, data analysis, and manuscript writing. YH: screening, coding of included articles, data summary, and manuscript writing. YZ: advice, data analysis, and manuscript writing.

Funding None.

Availability of data and materials Data are available from the authors upon reasonable request.

\section{Compliance with ethical standards}

Conflict of interest The authors declare that they have no competing interests.

Ethics approval and consent to participate Not applicable.

Consent for publication Not applicable.

Open Access This article is licensed under a Creative Commons Attribution 4.0 International License, which permits use, sharing, adaptation, distribution and reproduction in any medium or format, as long as you give appropriate credit to the original author(s) and the source, provide a link to the Creative Commons licence, and indicate if changes were made. The images or other third party material in this article are included in the article's Creative Commons licence, unless indicated otherwise in a credit line to the material. If material is not included in the article's Creative Commons licence and your intended use is not permitted by statutory regulation or exceeds the permitted use, you will need to obtain permission directly from the copyright holder. To view a copy of this licence, visit http://creativecommons.org/licenses/by/4.0/. 


\section{Appendix 1}

Search strategy in each database.

\section{Appendix 1 Search strategy in each database}

1. Cochrane $<1996$ to September 2019>

\#1 MeSH descriptor: [Endometriosis] explode all trees 768

\#2 MeSH descriptor: [Dyspareunia] explode all trees 178

\#3 MeSH descriptor: [Dysmenorrhea] explode all trees 569

\#4 MeSH descriptor: [Adenomyosis] explode all trees 33

\#5 (Endometriosis or dyspareunia or dysmenorrhea or dyschezia or adenomyosis):ti,ab (Word variations have been searched) $\quad 4241$

\#6 (pelvi* near/2 pain*):ti,ab 1571

$\# 7 \# 1$ or \#2 or \#3 or \#4 or \#5 or \#6 5429

\#8 MeSH descriptor: [Dydrogesterone] explode all trees 170

\#9 (dydrogesteron* or "6 dehydroretroprogesterone" or "6 dehydro 9 beta 10 alpha progesterone" or "6dehydro-9 beta-10 alpha-progesterone" or "9beta,10alpha pregna 4,6 diene 3,20 dione" or dehydrogesterone or dehydrogesterone or dufaston or duphaston or duvaron or gestatron or gynorest or hydrogesterone or isopregnenone or prodel or retrone or terolut):ti,ab 318

\#10 \#8 or \#9 342

\#11 \#7 and \#10 19

2. Embase $<1974$ to 2019 September $19>$

$1 \quad \exp$ ENDOMETRIOSIS/ (35450)

2 exp DYSMENORRHEA/ (11339)

3 exp DYSPAREUNIA/ (9879)

$4 \quad$ exp adenomyosis/ (4591)

5 (Endometriosis or dyspareunia or dysmenorrhea or dyschezia or adenomyosis).tw,kw. (44645)

6 (pelvi* adj2 pain*).tw,kw. (16214)

7 or/1-6 (69247) 
$8 \quad$ exp dydrogesterone/ (1924)

9 (dydrogesteron* or "6 dehydroretroprogesterone" or "6 dehydro 9 beta 10 alpha progesterone" or "6-dehydro-9 beta-10 alpha-progesterone" or "9beta,10alpha pregna 4,6 diene 3,20 dione" or dehydrogesterone or dehydrogesterone or dufaston or duphaston or duvaron or gestatron or gynorest or hydrogesterone or isopregnenone or prodel or retrone or terolut).tw,kw. (1122)

$10 \quad$ or/8-9 (1995)

$11 \quad 7$ and $10(249)$

3. Ovid MEDLINE(R) ALL <1946 to September 18, 2019>

$1 \quad \exp$ Endometriosis/ (21042)

2 exp Dyspareunia/ (2060)

3 exp Dysmenorrhea/ (3855)

$4 \quad$ exp Adenomyosis/ (649)

5 (Endometriosis or dyspareunia or dysmenorrhea or dyschezia or adenomyosis).tw,kw,kf. (30794)

6 (pelvi* adj2 pain*).tw,kw,kf. (9717)

$7 \quad$ or/ $1-6(42775)$

$8 \quad$ exp Dydrogesterone/ (479)

9 (dydrogesteron* or "6 dehydroretroprogesterone" or "6 dehydro 9 beta 10 alpha progesterone" or "6-dehydro-9 beta-10 alpha-progesterone" or "9beta,10alpha pregna 4,6 diene 3,20 dione" or dehydrogesterone or dehydrogesterone or dufaston or duphaston or duvaron or gestatron or gynorest or hydrogesterone or isopregnenone or prodel or retrone or terolut).tw,kw,kf. (526)

10 or/8-9(651)

117 and $10(53)$

4. Pubmed $<1996$ to September 2019>

Search Query Items found

\#8 Search (\#4 and \#7) 53 
\#7 Search (\#5 or \#6) 651

\#6 Search (dydrogesteron*[Text Word] OR "6 dehydroretroprogesterone"[Text Word] OR "6 dehydro 9 beta 10 alpha progesterone"[Text Word] OR "6-dehydro-9 beta-10 alpha-progesterone"[Text Word] OR "9beta,10alpha pregna 4,6 diene 3,20 dione"[Text Word] OR dehydrogesterone[Text Word] OR dehydrogesterone[Text Word] OR dufaston[Text Word] OR duphaston[Text Word] OR duvaron[Text Word] OR gestatron[Text Word] OR gynorest[Text Word] OR hydrogesterone[Text Word] OR isopregnenone[Text Word] OR prodel[Text Word] OR retrone[Text Word] OR terolut[Text Word]) 651

\#5 Search "Dydrogesterone"[Mesh] 480

\#4 Search (\#1 or \#2 or \#3) 57016

\#3 Search (pelvi*[Text Word]) AND pain*[Text Word]] 25288

\#2 Search (Endometriosis[Text Word] OR dyspareunia[Text Word] OR dysmenorrhea[Text Word] OR dyschezia[Text Word] OR adenomyosis[Text Word]) 36163

\#1 Search ((("Endometriosis"[Mesh]) AND "Dyspareunia"[Mesh]) OR "Dysmenorrhea"[Mesh]) OR "Adenomyosis"[Mesh] 4537

5. $\quad$ CNKI $<1999$ to September $2019>$

$(\mathrm{SU}=$ 地屈孕酮+地屈孕酮片+达芙通 $\mathrm{OR} \mathrm{AB}=$ 地屈孕酮+地屈孕酮片+达芙通) $\mathrm{AND}(\mathrm{SU}=$ 子宫内膜异 位症+子宫内膜异位+子宫腺肌病+子宫腺肌症+痛经+性交疼痛+性交痛 $\mathrm{OR} A B=\}$ 宫内膜异位症 + 子宫内膜异位+子宫腺肌病+子宫腺肌症+痛经+性交疼痛+性交痛) 71 条, 四库去重后共 93 条

6. Wanfang $<1980$ to September $2019>$

主题:("地屈孕酮"+"地屈孕酮片"+"达芙通")*("子宫内膜异位症"+"子宫内膜异位"+"子宫腺肌病"+"子 宫腺肌症"+"痛经"+"性交疼痛"+"性交痛") 79 条，去重后 22 条

7. VIP $<2000$ to September $2019>$ 
$(\mathrm{M}=$ 地屈孕酮+地屈孕酮片+达芙通 $\mathrm{OR} \mathrm{R}=$ =地屈孕酮+地屈孕酮片+达芙通) AND ( $\mathrm{M}=$ 子宫内膜异位 症 + 子宫内膜异位 + 子宫腺肌病+子宫腺肌症 + 痛经 + 性交疼痛 + 性交痛 $\mathrm{OR} R=$ 子宫内膜异位症 + 子 宫内膜异位+子宫腺肌病+子宫腺肌症+痛经+性交疼痛+性交痛) 58 条, 去重后 0 条

\title{
8. $\quad \mathrm{CBM}<1978$ to September 2019>
}

\author{
\#1. "子宫腺肌病"[不加权:扩展] \\ \#2. "子宫内膜异位症"[不加权:扩展] \\ \#3. 子宫内膜异位症 $\mathrm{OR}$ 子宫内膜异位 $\mathrm{OR}$ 子宫腺肌病 $\mathrm{OR}$ 子宫腺肌症 OR 痛经 OR 性交疼痛 OR \\ 性交痛
}

\#4. 地屈孕酮 OR 地屈孕酮片 OR 达芙通

\#5. (\#1 OR \#2 OR \#3) AND \#4 50 条, 去重后 0 条

\section{References}

1. Dunselman GAJ, Vermeulen N, Becker C, Calhaz-Jorge C, D'Hooghe T, Bie BD et al (2014) ESHRE guideline: management of women with endometriosis. Hum Reprod 29(3):400-412

2. Meuleman C, Vandenabeele B, Fieuws S, Spiessens C, Timmerman D, D'Hooghe T (2009) High prevalence of endometriosis in infertile women with normal ovulation and normospermic partners. Fertil Steril 92(1):68-74

3. Missmer SA, Hankinson SE, Spiegelman D, Barbieri RL, Marshall LM, Hunter DJ (2004) Incidence of laparoscopically confirmed endometriosis by demographic, anthropometric, and lifestyle factors. Am J Epidemiol 160:784-796

4. La Rosa VL, De Franciscis P, Barra F, Schiattarella A, Török P, Shah M, Karaman E, Marques Cerentini T, Di Guardo F, Gullo G, Ponta M, Ferrero S (2020) Quality of life in women with endometriosis: a narrative overview. Minerva Med 111(1):68-78

5. La Rosa VL, De Franciscis P, Barra F, Schiattarella A, Tropea A, Tesarik J, Shah M, Kahramanoglu I, Marques Cerentini T, Ponta M, Ferrero S (2020) Sexuality in women with endometriosis: a critical narrative review. Minerva Med 111(1):79-89

6. Laganà AS, Garzon S, Götte M, Viganò P, Franchi M, Ghezzi F, Martin DC (2019) The pathogenesis of endometriosis: molecular and cell biology insights. Int J Mol Sci 20(22):5615

7. Laganà AS, Vitale SG, Salmeri FM, Triolo O, Ban Frangež H, Vrtačnik-Bokal E, Stojanovska L, Apostolopoulo V, Granese R, Sofo V (2017) Unus pro omnibus, omnes pro uno: a novel, evidence-based, unifying theory for the pathogenesis of endometriosis. Med Hypotheses 103:10-20

8. Ahn SH, Monsanto SP, Miller C, Singh SS, Thomas R, Tayade C (2015) Pathophysiology and immune dysfunction in endometriosis. Biomed Res Int 2015:795976
9. Vitale SG, Capriglione S, Peterlunger I, La Rosa VL, Vitagliano A, Noventa M, Valenti G, Sapia F, Angioli R, Lopez S, Sarpietro G, Rossetti D, Zito G (2018) The role of oxidative stress and membrane transport systems during endometriosis: a fresh look at a busy corner. Oxidative Med Cell Longev 2018:7924021

10. National Institute for Health and Care Excellence (2017) Endometriosis: diagnosis and management. UK.

11. American Society for Reproductive Medicine (2012) Endometriosis and infertility: a committee opinion. Fertil Steril 98(3):591-598

12. Liu H, Dai Y, Huo Y, Zhao J, Sun X, Bai Y et al (2019) Application of modified version of Chinese medicine clinical pathway for dysmenorrhea in staging treatment of endometriosis-associated infertility. J Reprod Med 28(7):772-776

13. Griesinger G, Tournaye H, Macklon N, Petraglia F, Arck P, Blockeel C et al (2019) Dydrogesterone: pharmacological profile and mechanism of action as luteal phase support in assisted reproduction. Reprod Biomed Online 38(2):249-259

14. Rižner TL, Brožič P, Doucette C, Turek-Etienne T, Muller-Vieira U, Sonneveld E et al (2011) Selectivity and potency of the retroprogesterone dydrogesterone in vitro. Steroids 76(6):607-615

15. Taylor PJ, Kredentser JV (1992) Nonsurgical management of minimal and moderate endometriosis to enhance fertility. Int $\mathbf{J}$ Fertil 37(3):138-143

16. Johnston WIH (1976) Dydrogesterone and endometriosis. Br J Obstetr Gynaecol 83(1):77-80

17. Tagreed H, Mohanad M, Hayder F (2018) Comparison of the efficacy and safety between dienogest and dydrogesterone in treatment of endometriosis: prospective study. Int J Sci Res 7:1704-1707

18. Creutzfeldt CJ, Weinstein JR, Longstreth WT Jr, Becker KJ, McPharlin TO, Tirschwell DL (2009) Prior antiplatelet therapy, 
platelet infusion therapy, and outcome after intracerebral hemorrhage. J Stroke Cerebrovasc Dis 18(3):221-228

19. Cornillie FJ, Puttemans P, Brosens IA (1987) Histology and ultrastucture of human endometriotic tissues treated with dydrogesterone (Duphaston). Eur J Obstet Gynecol Reprod Biol 26(1):39-55

20. Overton CE, Lindsay PC, Johal B, Collins SA, Siddle NC, Shaw RW et al (1994) A randomized, double-blind, placebo-controlled study of luteal phase dydrogesterone (Duphaston*) in women with minimal to mild endometriosis. Fertil Steril 62(4):701-707

21. Trivedi P, Selvaraj K, Mahapatra PD, Srivastava S, Malik S (2007) Effective post-laparoscopic treatment of endometriosis with dydrogesterone. Gynecol Endocrinol 23(SUPPL. 1):73-76

22. Feng Y (2016) Clinical effect of progesterone in patients received endometriosis surgery and influence on pregnancy outcome. $\mathrm{J}$ Minim Invasive Med 11(4):513-515

23. Ji Y (2015) Observation on the clinical effect of Duphaston in treating 60 cases of endometriosis. Med Inf 28(3):53-54

24. Li S (2016) Application effect comparison of dydrogesterone and gestrinone in ovarian endometriosis patients after conservative surgery. China Mod Med 23(5):146-148

25. Li X, He C, Wu D, Wu F (2015) Therapeutic effects of dydrogesterone and gestrenene on endometriosis after operation. Clin Med China 31(3):269-272

26. Li Y (2019) Clinical observation of 90 cases of endometriosis treated with Duphaston. J Pract Gynecol Endocrinol 6(6):43-49

27. Liu J (2017) The postoperative comparative study of digesterone and gestrinone for ovarian endometriosis. Contemp Med 23(18): $160-161$

28. Liu J (2016) Clinical observation of dydrogesterone and gestrinone after surgical treatment of endometriosis. Matern Child Health Care China 31(1):197-199

29. Luo Y (2017) The effect of dydrogesterone on serum CA 125 in patients with endometriosis. Shanxi Med J 46(3):402-404

30. Wang Y, Huang J (2018) Effect of dydrogesterone treatment on serum CA125 in patients with endometriosis. J Med Aesthet Cosmetol 27(23):54

31. Xie Z, Yang B, Qian L (2019) Postoperative effect of didroxyprogesterone tablets in patients with endometriosis and related factor levels. Chin Rem Clin 19(3):468-470

32. Zhang L, Liu W (2013) Therapeutic effects of two types of progestogen on endometriosis after laparoscopic operation. Chin J Healthy Birth Child Care 19(2):93-95
33. Orazov MR, Radzinsky VY, Khamoshina MB, Kostin IN, Toktar LR, Kavteladze EV et al (2019) The efficacy of combined management of endometriosis-associated infertility. Int J Pharm Res 11(3):1001-1006

34. Walker SM (1982) The treatment of endometriosis with dydrogesterone. Br J Clin Pract 2:S40-46

35. Makhmudova GM, Nazhmutdinova DK, Gafarova D, Lukmanova I (2003) Efektivnost na lechenieto s duphaston na zheni prekarali rekonstruktivno-plastichni operatsii pri endometrioza [Efficacy of duphaston treatment in women with endometriosis after reconstructive surgery]. Akusherstvo i ginekologiia 42(4):42-46

36. Brown J, Kives S, Akhtar M (2012) Progestagens and antiprogestagens for pain associated with endometriosis (Review). Cochrane Database Syst Rev 14(3):002122

37. Telimaa S, Puolakka J, Ronnberg L, Kauppila A (1987) Placebocontrolled comparison of danazol and high-dose medroxyprogesterone acetate in the treatment of endometriosis. Gynecol Endocrinol 1(1):13-23

38. Telimaa S (1988) Danazol and medroxyprogesterone acetate inefficacious in the treatment of infertility in endometriosis. Fertil Steril 50(6):872-875

39. Devroey P (2003) Ovarian stimulation regimens in women with endometriosis. J Gynecol Obstet Biol Reprod 32(8):S42-S44

40. Laganà AS, Vitale SG, Trovato MA, Palmara VL, Rapisarda AM, Granese R, Sturlese E, De Dominici R, Alecci S, Padula F, Chiofalo B, Grasso R, Cignini P, D'Amico P, Triolo O (2016) Fullthickness excision versus shaving by laparoscopy for intestinal deep infiltrating endometriosis: rationale and potential treatment options. Biomed Res Int 2016:3617179

41. Raffaelli R, Garzon S, Baggio S, Genna M, Pomini P, Laganà AS, Ghezzi F, Franchi M (2018) Mesenteric vascular and nerve sparing surgery in laparoscopic segmental intestinal resection for deep infiltrating endometriosis. Eur J Obstet Gynecol Reprod Biol 231:214-219

Publisher's Note Springer Nature remains neutral with regard to jurisdictional claims in published maps and institutional affiliations. 